\title{
The safety of Osmanthus fragrans ethanol extract treatment in BALB/c mice
}

\author{
Chih-Hung Lin ${ }^{1}$, Kuo-Yu Li ${ }^{2}$, Tsung-Jen Hung ${ }^{3}$, Fu-Long Huang ${ }^{4}$, Chien-Ya Hung ${ }^{2} *$ \\ ${ }^{I}$ Department of optometry, Chung Hwa university of medical technology, Tainan city, Taiwan \\ ${ }^{2}$ Department of food nutrition, Chung Hwa university of medical technology, Tainan city, Taiwan \\ ${ }^{3}$ Department of graduate institute of biomedical science, Chung Hwa university of medical technology, Tainan, Taiwan \\ ${ }^{4}$ Graduate Institute of Food Science, National Chiayi University, Chiayi City, Taiwan \\ *Corresponding author E-mail: chienya187@yahoo.com.tw
}

\begin{abstract}
Background: Osmanthus fragrans flower, recently certificated as a new natural antioxidant, has been used in various foods. We performed an acute and subacute toxicological test for evaluating the safety and toxicity of $75 \%$ ethanol extraction of Osmanthus fragrans (OFEE).

Method: In the acute toxicity study, a single dose of $5 \mathrm{~g} / \mathrm{kg}$ and $10 \mathrm{~g} / \mathrm{kg}$ of the extract was administered orally to six mice. General behaviour, mortality and toxic symptoms were determined daily for 14 days. For the subacute toxicity, two groups of 12 mice received $0.9 \%$ normal saline (control) and $1 \mathrm{~g} / \mathrm{kg}$ of the extract daily for 28 consecutive days by oral gavage. The animals were observed daily for abnormal clinical signs and death. Body weight, haematological and biochemical parameters of blood as well as kidney, liver, lung and spleen tissues histology were evaluated.

Results: The total phenolic contents in OFEE were $371.71 \pm 12.35 \mathrm{mg}$ GAE/g extracts and total flavonoid contents were $47.23 \pm 5.36$ $\mathrm{mg}$ QE/g extract. OFEE did not cause any mortality or morbidity. Maximum tolerated dose (MTD) was $10 \mathrm{~g} / \mathrm{kg}$ body weight in our $\mathrm{BALB} / \mathrm{c}$ mice, which can be regarded as virtually non-toxic. Administration of OFEE at dose $1 \mathrm{~g} / \mathrm{kg} / \mathrm{day}$ for 28 -day did not cause changed in hematological, biochemical assay, and histopathological conditions change, suggesting a no-observed-adverse-effect level (NOVEL) of $1 \mathrm{~g} / \mathrm{kg} / \mathrm{day}$.

Conclusion: We found no evidence of adverse effects in our laboratory test and pathological studies. $75 \%$ ethanol extraction may safely be used in the research of Osmanthus fragrans in animal and probably human studies.
\end{abstract}

Keywords: Acute toxicity test, antioxidant activity, osmanthus fragrans, subacute toxicity test, total phenolic and flavonoid content.

\section{Introduction}

Osmanthus fragrans, also known as sweet osmanthus of sweet olive, is a species of Osmanthus, which is native to Asia and, found from the eastern Himalayas through southern China and as far as Taiwan and southern Japan (Huxley 1992, Cochinch 1996). The flower of $O$. fragrans, called Kwai-fah in China, has been used as a beverage and as an additive for tea and foods, condiments, and beverages. It is popular because of its delicate fruity/floral aroma. Traditional Chinese medicine has applied $O$. fragrans in the treatment of weakened vision, halitosis, panting, asthma, cough, toothache, stomachache, diarrhea, and hepatitis. Although research for the biomedical use of the extract of $O$. fragrans flowers is limited, there is some evidence showing that the $O$. fragrans may be a promising source of natural antioxidants (Kihuchi 1984, Lee et al. 2007, Wang et al. 2010, Hung et al. 2012a). Lee et al. (2007) found dried flowers of $O$. fragrans to have abundant level of phenols and flavonoids and to exhibit antioxidant activity in the metal reducing, FRAP assay, the DPPH, and hydroxyl anion scavenging ability (Lee et al. 2007). Our group has analyzed many antioxidant components of $O$. fragrans flowers and found their antioxidant activity to be slightly weaker than that of green tea (Hung et al. 2012a).
Although there are no in vivo studies into therapeutic activity of $O$. fragrans, some in vitro investigation have studied its bioactivity. It has been found to inhibit lipid peroxidation through ferrous chloride in the mitochondria in rat brain, liver, heart, and kidney (Lee et al. 2007). It may also exert neuroprotective actions through its upregulation of the AKT survival pathway, attenuating neurotoxicity (Lee et al. 2007). Several lignans isolated from the flowers of $O$. fragrans var. aurantiacus were found to inhibit nitric oxide production in lipopolysaccharide (LPS)-stimulated RAW 264.7 macrophages (Lee et al. 2011). In addition, our team found that the $O$. fragrans flower extract to have anti-depressive (Hung et al. 2012b), anti-allergic (Tu et al. 2013) and anti-pulmonary fibrosis capabilities (Hung \& Ye, 2011). All of these studies showed a strong enhanced antioxidant status after the consumption of the extract from the $O$. fragrans flower.

Recently, our group reported that $O$. fragrans flower beverage supplementation upregulated antioxidant parameters, including ORAC, GSH, GSSG, and GSH/GSSG ratio, GPx and SOD, in adults. After seven days of daily consuming $250 \mathrm{~mL}$ of a beverage made by brewing $2 \mathrm{~g}$ of dry $O$. fragrans flower in $1 \mathrm{~L}$ of water, subjects were found to have increased plasma ORAC activity, increased GSH and GPx content, and decreased GSSG, suggesting 
that consumption of this beverage might increase the antioxidant defense of the healthy individuals (Li et al. 2013).

In the aforementioned study, five phenolic compounds, including tyrosyl acetate (1), (+)-phillygenin (2), (8E)-ligustroside (3), rutin (4), and verbascoside (5), were isolated from the $\mathrm{CHCl}_{3}$ layer of $O$. fragrans. Evaluation of the antioxidative properties of the isolated compounds (2), (4), and (5) revealed strong 1, 1-diphenyl-2picryl-hydrazyl (DPPH) radical-scavenging activity and $\mathrm{H}_{2} \mathrm{O}_{2-}$ scavenging ability. A higher percentage of rutin and verbascoside was found in an ethanol than a methanol extract of $O$. fragrans (data not shown). Considering that these findings suggest that further research in vivo studies, we decided to evaluate the safety of the $75 \%$ ethanol extract of $O$. fragrans (OFEE). To do this, we conducted an acute and subacute toxicity test, following the safety assessment guidelines developed by the Department of Health of Taiwan (DOH 1999, Mehta et al. 2009). In both, female BALB/c mice were randomized to control and study groups which received an oral administration of OFEE. In the acute toxicity test, $5 \mathrm{~g} / \mathrm{kg}$ and $10 \mathrm{~g} / \mathrm{kg}$ of OFEE were administered (Cheng et al. 2010) and in the subacute toxicity study $1 \mathrm{~g} / \mathrm{kg}$ was administered daily for 28 consecutive days.

\section{Materials and methods}

\subsection{Animals}

Healthy 6-week-old female mice (BALB/c, body weight, 16-18 g), obtained from Biolasco Taiwan Co., Ltd. (I-Lan, Taiwan), received a general physical examination when we received them and were acclimatized for 7 days. The animals were housed in cages (6 per cage) and provided with food (Lab Diet 5001 Rodent diet; Purina Mills LLC, St. Louis, MO, USA) and water ad libitum. The stainless steel cages were kept at $21 \pm 2{ }^{\circ} \mathrm{C}$ with $50-70 \%$ humidity under a 12-h light/12-h dark cycle. This study was approved by the Institutional Animal Care and Use Committee (IACUC) of Chung Hwa University of Medical Technology (IACUC: A9311).

\subsection{Plant material}

The dried flowers of $O$. fragrans were purchased from a traditional market at Guilin, Guangxi Province, China, in 2009. The samples were authenticated by Dr. Mo-shin Tang, Department of Pharmaceutical Sciences and Technology, Chung Hwa University of Medical Technology. Voucher specimen of $O$. fragrans (HCY091001) has been deposited at the herbarium of the Department of Food Nutrition, Chung Hwa University of Medical Technology, and Tainan, Taiwan.

\subsection{Preparation}

The dried flowers of $O$. fragrans were ground into a fine powder using a mill (RT-08, Rong Tsong, Taiwan), collected, sealed in a polyethylene plastic bag, and stored at $0-4^{\circ} \mathrm{C}$ for further use. For extraction, O. fragrans flowers $(200 \mathrm{~g})$ were soaked $(72 \mathrm{~h}) 75 \%$ ethanol $(3 \mathrm{~L})$ twice and filtered through Whatman No. 1 filter paper. The combined extracts were concentrated under reduced pressure and freeze-dried to obtain dark syrup, which was stored at $-20{ }^{\circ} \mathrm{C}$ for further use. The extraction yield of $75 \%$ ethanol extract was presented as \% weight (gram of $75 \%$ ethanol extract for each $100 \mathrm{~g}$ of dry herbs) and the results are shown in Table 1.

\subsection{Determination of total phenolic content}

As described by Yen \& Hung (2000), we mixed the sample solution in methanol $(0.1 \mathrm{~mL}, 1 \mathrm{mg} / \mathrm{mL})$ with $2 \% \mathrm{Na}_{2} \mathrm{CO}_{3}(2 \mathrm{~mL})$. After $3 \mathrm{~min}, 50 \%$ Folin-Ciocalteaure agent $(0.1 \mathrm{~mL})$ was added. The mixture was allowed to stand at room temperature for $30 \mathrm{~min}$ with intermittent mixing. The absorbance at $750 \mathrm{~nm}$ was recorded A standard curve using gallic acid was prepared. The total phenol- ic content was expressed as gallic acid equivalents ( $\mathrm{mg}$ of GAE per $g$ extract).

\subsection{Determination of total flavonoid content}

Following the methods described by Woisky \& Salatino (1998) and also by Chang et al. (2002), $0.5 \mathrm{~mL}$ of sample solution was mixed with $1.5 \mathrm{~mL}$ of $95 \%$ ethanol, $0.1 \mathrm{~mL}$ of $10 \% \mathrm{AlCl}_{3}, 0.1 \mathrm{~mL}$ of $1 \mathrm{M} \mathrm{KOAc}$, and $2.8 \mathrm{~mL}$ of distilled water. The mixture was allowed to stand at room temperature for $30 \mathrm{~min}$, and absorbance was measured at $415 \mathrm{~nm}$. The amount of sample solution was substituted by the same amount of a quercetin solution (0-200 $\mu \mathrm{g} / \mathrm{mL}$ ) as a standard. The amount of $10 \% \mathrm{AlCl}_{3}$ was substituted by the same amount of distilled water as a blank. Total flavonoid content was calculated from the plot of absorbance against quercetin concentration using linear regression analysis and expressed as quercetin equivalents ( $\mu \mathrm{g}$ of $\mathrm{QE}$ per g extract).

\subsection{DPPH free radical scavenging assay}

DPPH is a stable free radical that has a purple color which is reduced to a colorless compound by antioxidants. We used DPPH in an assay method modified by Shimada et al. (2002). Methanol (3.8 $\mathrm{mL})$, sample solution in methanol $(0.2 \mathrm{~mL}, 1 \mathrm{mg} / \mathrm{mL})$ and $1 \mathrm{mM}$ DPPH solution $(1.0 \mathrm{~mL})$ were mixed well and left to stand in the dark at room tempertrue for $30 \mathrm{~min}$. The final concentration of the sample was $40 \mu \mathrm{g} / \mathrm{mL}$. The absorbance at $517 \mathrm{~nm}$ was measured. The sample in methanol was used as a blank, and the DPPH radical in methanol solution was used as a control. The DPPH radical scavenging activity was calculated using the equation:

$\%$ of DPPH radical scavenging activity $=\left[1-\left(\mathrm{A}_{\text {sample }}-\right.\right.$ $\left.\left.\mathrm{A}_{\text {blank }}\right) / \mathrm{A}_{\text {control }}\right] \times 100$, where $\mathrm{A}$ is the absorbance at $517 \mathrm{~nm}$.

The concentration providing $50 \%$ inhibition $\left(\mathrm{IC}_{50}\right)$ DPPH radical scavenging activity was calculated from the plot of inhibition percentage against sample concentration by linear regression.

\subsection{Oxygen radical absorbance capacity (ORAC) assay}

The total antioxidant activity of the organ samples was measured by using the oxygen radical absorbance capacity (ORAC) assay according to Chung et al. (2005). This assay was carried out in black-walled, 96 -well plates at $37^{\circ} \mathrm{C}$. All solutions were prepared in $75 \mathrm{mM}$ phosphate buffer $\left(\mathrm{Na}_{2} \mathrm{HPO}_{4}: \mathrm{NaH}_{2} \mathrm{PO}_{4}, \mathrm{pH} 7.0\right)$ and preincubated at $37^{\circ} \mathrm{C}$ for $30 \mathrm{~min}$ before use. $15 \mu \mathrm{L}$ of organ homogenate (diluted 100 times) and $100 \mu \mathrm{L}$ of $0.1 \mu \mathrm{M} \beta$-PE ( $\beta$ phycoerythrin) were transferred directly into the well to incubate for 10 min using the FLUOstar OPTIMA microplate reader system (Galaxy BMG LABTECH Inc., Cary, NC). $85 \mu \mathrm{L}$ of $75 \mathrm{mM}$ 2, 2'-azobis (2-amidinopropane) dihydrochloride (AAPH) was added rapidly and the fluorescence measured immediately using fluorescence filters with an excitation wavelength of $480 \mathrm{~nm}$ and an emission wavelength of $520 \mathrm{~nm}$. The fluorescence was recorded at 5 min intervals for 120 min until the final value was less than $5 \%$ of the initial value. ORAC values from samples were calculated by using the following equation and expressed as Trolox equivalents: ORAC value $(\mathrm{mM})=20 \times \mathrm{k} \times\left(\mathrm{S}_{\text {sample }}-\mathrm{S}_{\text {blank }}\right) /\left(\mathrm{S}_{\text {Trolox }}-\right.$ $\mathrm{S}_{\text {blank }}$ ), where $\mathrm{k}$ is the sample dilution factor. The area under the curve $(\mathrm{S})$ was calculated by the following equation:

$\mathrm{S}=\left(0.5+\mathrm{f}_{5} / \mathrm{f}_{0}+\mathrm{f}_{10} / \mathrm{f}_{0}+\mathrm{f}_{15} / \mathrm{f}_{0}+\mathrm{f}_{20} / \mathrm{f}_{0}+\mathrm{f}_{25} / \mathrm{f}_{0}+\cdots \cdot \mathrm{f}_{120} / \mathrm{f}_{0}\right) \times$ 5

Where $\mathrm{f}_{0}$ was initial fluorescence reading at $0 \mathrm{~min}$ and fn represented measurement at time $\mathrm{n}$.

\subsection{Single-dose acute study assessing the toxic effects of OFEE treatment}

Female BALB/c mice were randomly assigned to a control group and two study groups treated with OFEE. The two study groups were treated with a single dose of $5 \mathrm{~g} / \mathrm{kg}$ and $10 \mathrm{~g} / \mathrm{kg}$ of OFEE, respectively. The control animals were gavaged with $0.9 \%$ nor- 
mal saline. The administration volume of $0.9 \%$ normal saline was $10 \mathrm{~mL} / \mathrm{kg}$ body weight. The animals were observed daily for signs of intoxication, including behavioral changes and changes body weight. Body weight was measured weekly for 14 days. On the next day, animals were anesthetized with pentobarbital and blood withdrawn via the abdominal aorta.

\subsection{8-day toxicity subacute study assessing the toxic effects of OFEE treatment}

Female BALB/c mice were gavaged with OFEE at the dose of 1 $\mathrm{g} / \mathrm{kg}$ orally for the 28 consecutive days. The control group was treated with $0.9 \%$ normal saline $(10 \mathrm{~mL} / \mathrm{kg})$. During the treatment period, weekly body weight and daily food consumption were recorded. On day 28 , all animals were fasted overnight. On the next day, animals were anesthetized with pentobarbital and then blood withdrawal for blood biochemical analysis.

\subsection{Histopathologic studies}

During autopsy, select vital organs (spleen, lungs, liver and kidneys) were excised, blotted and weighed. All organs were observed by microscope of $400 \mathrm{X}$. Tissues were fixed in $10 \%$ buffered neutral formalin. H\& E staining was also conducted.

\subsection{Hematological analysis}

Blood samples were analyzed for red blood cells (RBC) count, haemoglobin $(\mathrm{Hb})$, haematocrit (HCT), mean corpuscular haemoglobin $(\mathrm{MCH})$, and mean corpuscular haemoglobin concentration (MCHC), mean corpuscular volume (MCV), and white blood cells count (WBC). Haematological analyses were performed using a fully automated haematological analyser (Abbott Cell-Dyn 3500, Abbott Laboratories, IL, and USA).

\subsection{Serum biochemical analysis}

Blood samples were kept at room temperature for $1 \mathrm{~h}$, and then centrifuged at $1000 \mathrm{~g}$ for $10 \mathrm{~min}$ to obtain serum. The serum biochemical parameters, including glutamic oxaloacetic transaminase (GOT), glutamic pyruvic transaminase (GPT), blood urea nitrogen (BUN), creatinine, albumin (ALB) and total protein (TP) were assayed using commercially available kits from Randox Laboratories Co. (Antrum, UK).

\subsection{Statistics}

The results are expressed as mean \pm SD. Sample sizes are indicated by $n$. Variation analysis was performed using ANOVA software. Two-tailed unpaired student's t-test was used to compare the differences within a group or between groups. In all cases, a $\mathrm{p}$ value of $<0.05$ was considered significant

\section{Results}

\subsection{The total phenolic, flavonoid contents, DPPH scav- enging effects and ORAC of OFEE}

The total phenolic contents in OFEE were $371.71 \pm 12.35 \mathrm{mg}$ $\mathrm{GAE} / \mathrm{g}$ extracts and total flavonoid contents were $47.23 \pm 5.36 \mathrm{mg}$ $\mathrm{QE} / \mathrm{g}$ extract. As seen in Table 1, the ethanol extract of DPPH IC $\mathrm{I}_{50}$ was $8.6 \mu \mathrm{g} / \mathrm{mL}$, which was less than methanol extract $(12.8$ $\mu \mathrm{g} / \mathrm{mL}$ ), and trolox ( $4.9 \mu \mathrm{g} / \mathrm{mL}$ ) (Hung et al. 2012). As previously reported, $O$. fragrans was a rich phenolic- and flavonoid-content and found to exhibit great antioxidative activity (Hung et al 2012).

\subsection{Single-dose acute toxicity of OFEE in BALB/c mice}

During the 14-day post dosing observation period, all test mice appeared healthy and normal (data not shown). No abnormal signs or death was observed. The maximum tolerated dose (MTD) of 75 $\%$ ethanol extract of $O$. fragrans was more than $10.0 \mathrm{~g} / \mathrm{kg}$. Thus, the $75 \%$ ethanol extract of $O$. fragrans at $5 \mathrm{~g}$ and $10 \mathrm{~g} / \mathrm{kg}$ body weight had no acute toxic effect based on the criteria established for mice (Department of Health of Taiwan 1999).

\subsection{Body weight of mice treated for 28-day with OFEE}

Mice treated with $O$. fragrans extract for 28 consecutive days were weighted weekly. The mean group weekly body weights over time are presented in figure 1 . Body weight was found to be slightly increased on day 7, 14, and 28. (Day 0: controls $16.37 \pm$ 0.85 and OFEE treated groups $17.78 \pm 0.75$; Day 7: controls $19.27 \pm 1.18$ and OFEE treated groups $18.73 \pm 1.42$; Day 14 : controls $19.58 \pm 1.36$ and treated groups: $19.40 \pm 0.77$; Day 28 : controls $20.10 \pm 1.38$ and treated groups $19.38 \pm 1.08)(\mathrm{n}=6$ in each group, all $\mathrm{p}>0.1$ ). We found no significant differences in body weight changes between control and study groups. All weight changes were within the normal range, and, therefore, attributed to normal biological variation.

Table 1: The total phenolic, flavonoid contents, DPPH scavenging effects and ORAC in OFEE.

\begin{tabular}{cccccc}
\hline \multirow{2}{*}{$\begin{array}{c}\text { Extraction } \\
\text { yield }\end{array}$} & $\begin{array}{c}\text { Total } \\
\text { phenolic } \\
\text { contents }\end{array}$ & $\begin{array}{c}\text { Total } \\
\text { flavonoid } \\
\text { contents }\end{array}$ & $\begin{array}{c}\text { DPPH } \\
\text { scavenging } \\
\text { effects }\end{array}$ & ORAC \\
\cline { 2 - 6 } & $(\%)$ & $\begin{array}{c}\text { GAE/g } \\
\text { extract) }\end{array}$ & $\begin{array}{c}\text { extract) } \\
\text { (mg } / \mathrm{g}\end{array}$ & $\mathrm{IC}_{50}(\mu \mathrm{g} / \mathrm{mL})$ & $\begin{array}{c}\text { (mM trolox } \\
\text { equivalent) }\end{array}$ \\
& & 371.71 & $47.23 \pm$ & & $0.38 \pm$ \\
OFEE & 6.4 & \pm 12.35 & 5.36 & 8.6 & 0.02 \\
\hline
\end{tabular}

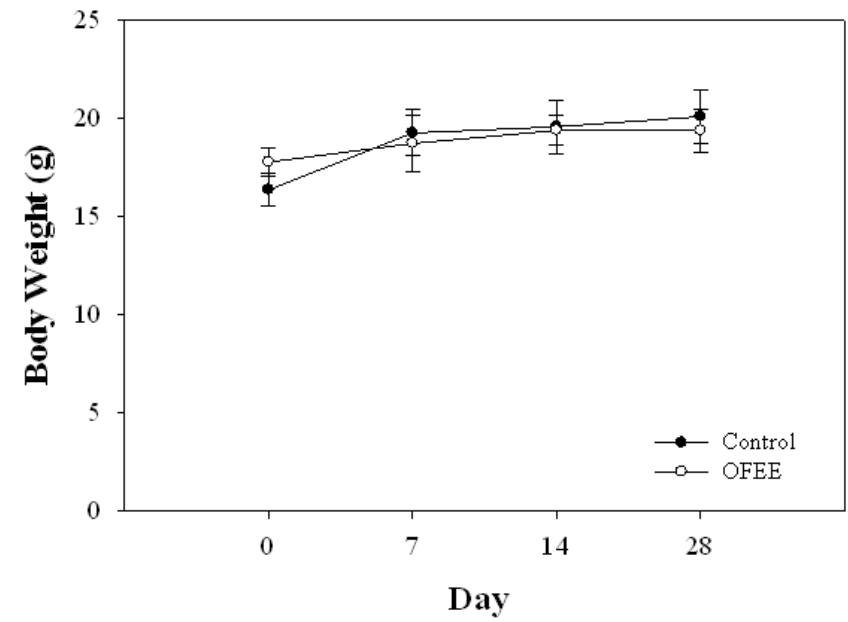

Fig. 1: Body weight changes of after oral administration with OFEE for 28-day. No significant difference was observed in the body weight of mice after daily gavage with OFEE or control group.

\subsection{Histopathologic assessment on the organs of mice treated for 28-day with OFEE}

Histopathological assessment is required to reveal the intoxication phenomena in organisms. The livers, spleens, lungs, and kidneys of mice treated with OFEE for 28-day was subjected to such an assessment. On day 29, mice received a detailed post-mortem examination of the internal organs. No macroscopic differences were found in size, color or texture of the organs. Microscopic findings on $\mathrm{H} \& \mathrm{E}$ stained sections are shown in fig. 2. No cellular atrophy, necrosis or any cellular damage in organ tissues was found (controls vs. treatment group: liver A1 and A2; spleen B1 and $\mathrm{B} 2$; lung $\mathrm{C} 1$ and $\mathrm{C} 2$; and kidney D1 and D2). Under micro- 
scope observation, no significant lesions were found in livers, kidney, spleen and lung of the treated mice. Morphological analysis of the kidney sections revealed no significant acute tubular injury, including vacuolization, loss of brush borders, sloughing of tubular cells into the lumen, or flattening of the tubular epithelium. The administration of OFEE did not affect liver tissue of mice, as evidence by a lack of morphological differences in the lining between the study mice and the controls. Hepatocellular cells were arranged in neat rows and showed, no signs of porridge necrosis or fibrosis, suggesting no portal chronic inflammation. The other vital organs (lung and spleen) appeared normal and did not show any alterations in structure. Analysis of tissues from the mice showed no feeding toxicity.
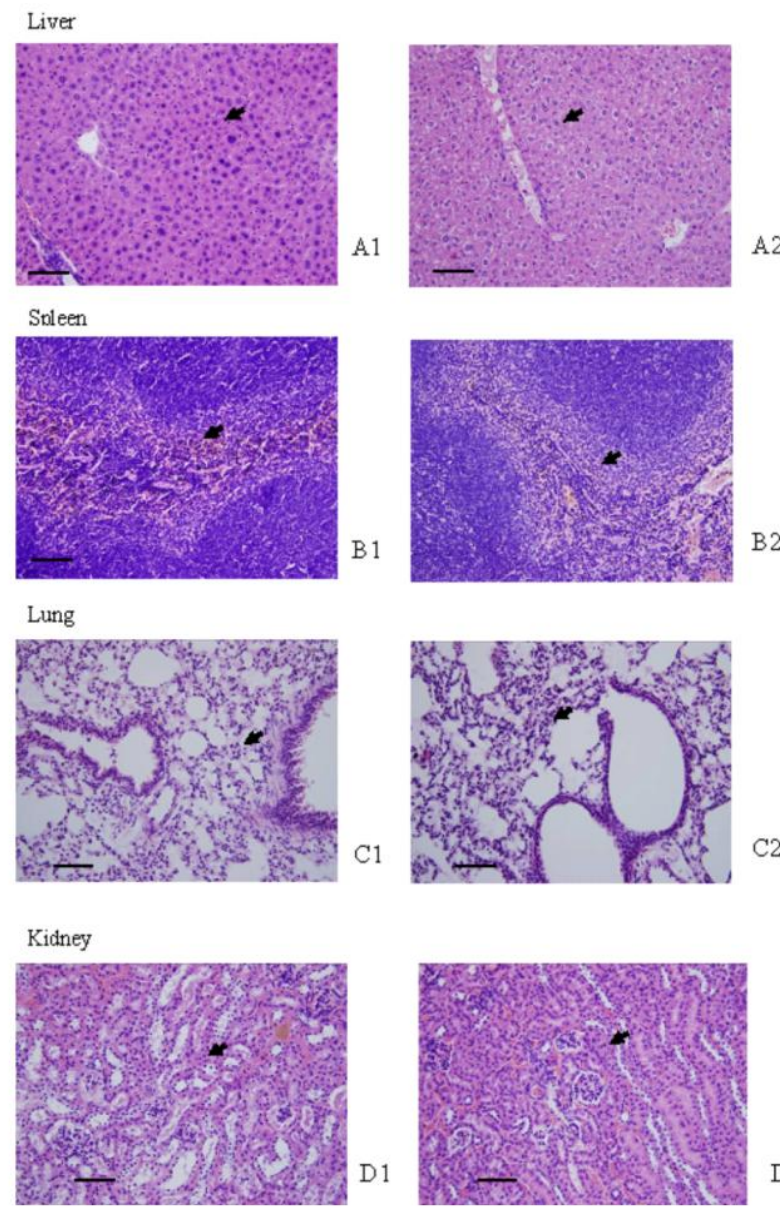

$\mathrm{C} 2$

Fig. 2: Histopathologic of liver in all treated groups with OFEE for 28day. A: Control; B: OFEE (Scale bar $=50 \mu \mathrm{m})(400 \mathrm{x})$.

\subsection{Hematological and biochemical assays performed for mice treated with OFEE for 28-day}

The results of hematological and biochemical assays are also crucial toxicological indices in organisms. We examined such indices, including white blood cell count (WBC), red blood cell count (RBC), hemoglobin ( $\mathrm{Hb})$, hematocrit (HCT), and mean cell volume (MCV) (Table 2). We also examined biochemical indices, including glutamate oxaloacetate transaminase (GOT), glutamicpyruvic transaminase (GPT), blood urea nitrogen (BUN), creatinine, albumin and total protein (TP). The administration of OFEE did not lead to increased activity of serum toxicity marker enzymes (GOT, GPT), indicating normal liver function (Table 3).

No significant difference was found any of the hematologically examined items between controls and study groups. Furthermore, no significant differences were found in any of the biochemically examined items between control and treatment groups.
Table 2: Hematological parameters in BALB/c mice treated with OFEE or control.

\begin{tabular}{ccccc} 
Hematological & Unit & control & OFEE & P value \\
\hline White blood cell & $\times 10^{9} / 1$ & $7.47(0.17)$ & $7.39(0.15)$ & 0.11 \\
Red blood cell & $\times 10^{12} / 1$ & $8.06(0.12)$ & $8.12(0.13)$ & 0.10 \\
Hemoglobin & $\mathrm{g} / \mathrm{dl}$ & $12.26(0.14)$ & $12.31(0.12)$ & 0.31 \\
Hematocrit & $\%$ & $44.83(2.95)$ & $46.33(3.01)$ & 0.08 \\
MCV & $\mathrm{fl}$ & $52.58(1.08)$ & $53.16(1.20)$ & 0.07 \\
MCH & $\mathrm{pg}$ & $15.39(0.20)$ & $15.49(0.14)$ & 0.08 \\
MCHC & $\mathrm{g} / \mathrm{dl}$ & $29.29(0.10)$ & $29.33(0.07)$ & 0.13 \\
& & & & \\
\hline
\end{tabular}

Table 3: Biochemistry parameters in BALB/c mice treated with OFEE or control.

\begin{tabular}{ccccc}
\hline Biochemistry & Unit & control & OFEE & P value \\
\hline GOT & $\mathrm{U} / \mathrm{l}$ & $181.84(2.25)$ & $180.52(1.39)^{*}$ & 0.038 \\
GPT & $\mathrm{U} / \mathrm{l}$ & $53.51(2.17)$ & $52.72(2.14)$ & 0.22 \\
BUN & $\mathrm{mg} / \mathrm{dl}$ & $24.04(0.29)$ & $23.88(0.15)$ & 0.065 \\
Creatinine & $\mathrm{mg} / \mathrm{dl}$ & $0.37(0.03)$ & $0.36(0.04)$ & 0.27 \\
ALB & $\mathrm{g} / \mathrm{l}$ & $31.76(0.37)$ & $31.57(0.31)$ & 0.07 \\
TP & $\mathrm{g} / \mathrm{l}$ & $58.82(0.39)$ & $58.77(0.40)$ & 0.65 \\
\hline
\end{tabular}

*Significant difference between the control group and OFEE group at $\mathrm{p}<$ 0.05

\section{Discussion}

To the best of our knowledge, there are no published studies on the toxicological profile of OFEE following acute and subacute exposure. In our acute toxicity study, a high dose of OFEE at 10 $\mathrm{g} / \mathrm{kg}$ was used expecting that it would induce some observable toxic effects in the BALB/c mice. However, this preliminary toxicological study found no such toxic effect up to $10 \mathrm{~g} / \mathrm{kg}$ body weight of OFEE when administered orally. Our subacute toxicity study (28-day) indicated the absence of cumulative toxicity and a no-observed-adverse-effect level (NOAEL) of $1 \mathrm{~g} / \mathrm{kg}$ of OFEE.

In the present studies, the results suggested that $75 \%$ ethanol can be safely used in the extraction of $O$. fragrans, as evidenced by no significant change in weight and no damage to the organ tissues in mice treated for 28-day consecutively. In addition, there were no significant differences in hematological and biochemical assay finding between the study group and controls. None of the mice subjected to our acute toxicity test died or showed any abnormalities. All tested mice appeared healthy and normal (data not shown).

The 28-day subacute toxicity study involved a dosage equivalent to human consumption of $937.5 \mathrm{~g} \mathrm{O}$. fragrans per $60 \mathrm{~kg}$ body weight per day. This is a 937.5 to 468.8 -fold higher dose than the estimated average human dietary intake (1-2 g O. fragrans/ 250 $\mathrm{mL}$ one cup per day). A commonly reported average dose of $O$. fragrans is about $15.625 \mathrm{~g}$ dried herb, which is equivalent to $1 \mathrm{~g}$ of the OFEE (yield of $75 \%$ ethanol extract $=6.4 \%$ of the dried material) considering an average body weight of an adult of 60 $\mathrm{Kg}$. This dose for a $60 \mathrm{~kg}$ human is equal to $60 \mathrm{~g}$ of OFEE /day, or $937.5 \mathrm{~g}$ O. fragrans/day.

As new drugs are developed, it is important to translate the drug dosage from one animal species to another, including humans. It has been evidenced that animal dose should not be extrapolated to a human equivalent dose (HED) by a simple conversion based on body weight. The evaluation of animal toxicity screening systems can be used as a tool to enable safe introduction of new drugs into humans, although the authors of those studies did not attempt to relate therapeutic doses in various species (Freireich et al. 1966, Schein et al. 1970). Reagan-Shaw et al. (2007) suggest using the body surface area (BSA) normalization method to obtain the most appropriate conversion of drug doses from animal studies to human studies. BSA correlates well across several mammalian species with several biological parameters, including oxygen utilization, caloric expenditure, basal metabolism, blood volume, circulating plasma proteins, and renal function. However, the Food and Drug Administration (2002) has suggested that the extrapolation of animal dose to human dose is correctly performed only through 
normalization to B.S.A., which often is represented in $\mathrm{mg} / \mathrm{m} 2$. Reagan-Shaw et al. (2007) advocate the use of BSA as a factor when converting a dose for translation from animals to humans. To convert the dose used in a mouse to a dose based on surface area for humans, multiply $1000 \mathrm{mg} / \mathrm{kg}$ (Baur's mouse dose) by the $3 \mathrm{Km}$ factor for a mouse and then divide by the $37 \mathrm{Km}$ factor for a human. This calculation results in a human equivalent dose for OFEE of $81.1 \mathrm{mg} / \mathrm{kg}$, which equates to a $4864.9 \mathrm{mg}$ dose of OFEE, or $76.01 \mathrm{~g} O$. fragrans for a $60 \mathrm{~kg}$ person. Based on these models of calculation, $O$. fragrans extract and $O$. fragrans flower beverages are safe.

\section{Conclusion}

In conclusion, based on evidence by our acute and sub-acute toxicity studies in rats in our study, the consumption of $O$. fragrans extract is safe. It can be used in herbal formulas without any toxic effects and be used safely in the development of health foods.

\section{Acknowledgement}

This study was supported by the Chung Hwa University of Medical Technology for the financial supporting under Contract No. Hwai-98-02003. The author would like to thanks Yu-Cheng Tsai and others for their helpful assistance in the laboratory. Here we also appreciated for the autopsy support from M.D. Chien-Feng, $\mathrm{Li}$, and the pathological department of Chi Mei Hospital in Tainan.

\section{Conflicts of Interest}

The authors declare no conflict of interest.

\section{References}

[1] Huxley A (1992) Ed. New RHS Dictionary of Gardening.

[2] Cochinch. Osmanthus Loureiro. Fl. Flora of China. (1996) 15, 286292.

[3] Kikuchi M (1984) Studies on the constituents of Osmanthus species. I. The components of the leaves of Osmanthus fragrans Lour. Var. aurantiacus Makino. 1. Yakugaku Zasshi 104, 535-539.

[4] Lee HH, Lin CT \& Yang LL (2007) Neuroprotection and free radical scavenging effects of Osmanthus fragrans. Journal of Biomedical Science 14, 819-827.

[5] Wang H, Gan D, Zhang X \& Pan Y (2010) Antioxidant capacity of the extracts from pulp of Osmanthus fragrans and its components. LWT - Food Science and Technology 43, 319-325.

[6] Hung CH, Tsai YC \& Li KY(2012) Phenolic Antioxidants Isolated from the Flowers of Osmanthus fragrans. Molecules 17, 10724-10737.

[7] Lee DG, Lee SM, Bang MH, Park HJ, Lee TH, Kim YH, Kim JY \& Baek NI (2011) Lignans from the flowers of Osmanthus fragrans var. aurantiacus and their inhibition effect on NO production. Archlive of Pharmacal Research 34, 2029-2035.

[8] Hung CY, Yang YH, Tsai YC, Hung MY \& Lin CH (2012) The effects of Osmanthus fragrans flower extract on maternally deprived rats in early life. Life Science Journal 9, 3173-3178.

[9] Tu, CH, Sun, YM, Tsai YC, Hung TJ, Chu HF \& Hung CY (2014) Osmanthus fragrans extracts for preventing noise induced hearing loss in brewery workers: a randomized, double-blind, controlled study Journal of Alternative and Complementary Medicine, in press.

[10]Hung CY \& Ye YL (2011) Extracted method of anti-asthmatic substances from Osmanthus fragrans. Taiwan patent number: I341205. May, 1.

[11]Li KY, Tsai YC \& Hung CY (2013) Effect of Osmanthus Fragrans flower beverage on antioxidant activity in healthy individuals. Taiwanese Journal of Agricultural Chemistry and Food Science 51, 7-16.

[12] Guideline assessment for food safety of health foods (1999) Department of Health (DOH). Taipei, Taiwan, R.O.C.

[13]Mehta AK, Arora N, Gaur SN \& Singh BP (2009) Acute toxicity assessment of choline by inhalation, intraperitoneal and oral routes in Balb/c mice. Regulatory Toxicology and Pharmacology 54, 282-286.
[14]Cheng YW, Lou HY, Lee SS, Liao JW, Chengi, HW, Li CH, Liao PL \& Kang JJ (2010) Safety assessment of musk substitute from nutria of yocastor Coypus in mice. Journal of Food and Drug Analysis 18, 380 390.

[15]Freireich EJ, Gehan EA, Rall DP, Schmidt LH \& Skipper HE (1966) Quantitative comparison of toxicity of anticancer agents in mouse, rat, hamster, dog, monkey, and man. Cancer Chemotherapy Reports 50, 219-244.

[16]Schein PS, Davis RD, Carter S, Newman J, Schein DR \& Rall DP (1970) The evaluation of anticancer drugs in dogs and monkeys for the prediction of qualitative toxicities in man. Clinical Pharmacology and Therapeutics 11, 3-40.

[17]Reagan-Shaw S, Nihal M \& Ahmad N (2007) Dose translation from animal to human studies revisited. Faseb Journal 22, 659-666.

[18]Estimating the safe starting dose in clinical trials for therapeutics in adult healthy volunteers (2002) Center for Drug Evaluation and Research, Center for Biologics Evaluation and Research, U.S. Food and Drug Administration, Rockville, Maryland, USA.

[19]Yen GC \& Hung CY (2000) Effects of alkaline and heat treatment on antioxidative activity and total phenolics of extracts from Hsian-tsao (Mesona procumbens Hemsl.). Food Research International 33, 487492.

[20]Woisky RG \& Salatino A (1998) Analysis of propolis: some parameters and procedures for chemical quality control. Journal of Apicultural Research 37, 99-105.

[21]Chang CC, Yang MH, Wen HM \& Chern JC (2002) Estimation of total flavonoid content in propolis by two complementary colorimetric methods. Journal of food and drug analysis 10, 178-182.

[22]Shimada K, Fujikawa K, Yahara K \& Nakamura T(1992) Antioxidative properties of xanthan on the autoxidation of soybean oil in cycodextrin emulsion. Journal of Agricultural and Food Chemistry $40,945$.

[23]Chung KY, Lee SJ, Chung SM, Lee MY, Bae ON \& Chung JH (2005) Generation of free radical by interaction of iron with thiols in human plasma and its possible significance. Thrombosis Research 116, 157 164. 